\title{
People's Republic of China Legal Update: The Notice on Further Strictly Regulating and Effectively Preventing Online Video Gaming Addiction in Minors (Published August 30, 2021, Effective September 1, 2021)
}

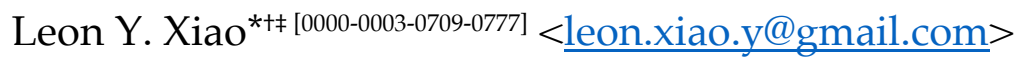 \\ *: The Honourable Society of Lincoln's Inn, Lincoln's Inn, London WC2A 3TL, \\ United Kingdom \\ +: The City Law School, City, University of London, Northampton Square, \\ Clerkenwell, London EC1V 0HB, United Kingdom
}

\section{Keywords (6):}

Video gaming; Video game regulation; Consumer protection law; Mainland China; Interactive entertainment law; Protection of minors

\section{Introduction}

The National Press and Publication Administration (NPPA) of the People's Republic of China published the Notice on Further Strictly Regulating and Effectively Preventing Online Video Gaming Addiction in Minors (the "2021 Notice") on August 30, 2021. ${ }^{1}$ The 2021 Notice becomes effective on September 1, 2021. The 2021 Notice updates (and, where incompatible, supersedes) the older regulatory requirements set out by the NPPA in the Notice on the Prevention of Online Gaming Addiction in Juveniles (the "2019 Notice") published nearly two years ago on 25 October $2019,{ }^{2}$ which was translated and discussed by Xiao at 24 GAMING LAW ReV. $51-53 .{ }^{3}$ The two Notices regulate video gaming in China and restrict minors' (defined as people under the age of 18) access to online video games. This International Gaming Industry Update compares

\footnotetext{
1 国家新闻出版署 [National Press and Publication Administration (PRC)], 国家新闻出版署关于进一步严格 管理切实防止末成年人沉迷网络游戏的通知 [Notice of the National Press and Publication Administration on Further Strictly Regulating and Effectively Preventing Online Video Gaming Addiction in Minors] 国新出发 （2021〕 14 号(2021), http://www.nppa.gov.cn/nppa/contents/279/98792.shtml (last visited Aug 30, 2021).

2 国家新闻出版署 [National Press and Publication Administration (PRC)], 关于防止末成年人沉迷网络游戏 的通知 [Notice on the Prevention of Online Gaming Addiction in Juveniles] 国新出发 (2019) 34 号 (2019), http://www.sapprft.gov.cn/sapprft/contents/6588/407807.shtml (last visited Nov 20, 2019).

${ }^{3}$ Leon Y. Xiao, People's Republic of China Legal Update: The Notice on the Prevention of Online Gaming Addiction in Juveniles (Published October 25, 2019, Effective November 1, 2019), 24 GaMing LAW Rev. 51$53(2020)$
} 
the old and new regulatory positions and comments on the implications of this regulatory development in China.

\section{Video Gaming Time: Maximum Limits and Timing Restriction}

The old position, as set out by Section 2 of the 2019 Notice, is that minors were allowed to play video games for 1.5 hours on weekdays, and 3 hours on weekends and public holidays. However, minors were not allowed to play video games between 22:00 and 8:00 the next morning on any day. This means that minors were allowed to play up to a total of 13.5 hours of video games during a normal week.

The new position, as set out by Section 1 of the 2021 Notice, is that minors are only allowed to play video games between 20:00 and 21:00 and that they are only allowed to do so on Fridays, Saturdays, Sundays, and public holidays. This means that minors are allowed to play up to a total of only 3 hours of video games during a normal week. This represents a reduction of 10.5 hours of video game playing time per week from the old regulatory position (i.e., a $77.8 \%$ reduction).

\section{Verification of Real-Life Identities of Users}

Section 1 of the 2019 Notice required video gaming service providers to verify the real-life identity of all users; however, the 2019 Notice also allowed service providers to offer a 'demo' or 'guest user' version of the game lasting less than one hour in length to users who have not verified their real-life identity (provided that the demo does not permit the user to spend real-world money on the game and that the demo is only provided to each hardware system at most only once every 15 days). This 'demo/guest user' proviso of the old regulatory position allowed for unverified users to play video games under certain limited circumstances.

Section 2 of the 2021 Notice now prohibits video gaming service providers from offering services to unverified users in all circumstances. The 'demo/guest user' proviso has been explicitly disallowed. All users' real-life identities must be verified in all circumstances before video gaming services may be provided to them.

\section{Practical Implications}

The 2021 Notice significantly reduces the number of hours that Chinese minors are permitted to play video games. Importantly, it also entirely prohibits minors from 
playing video games on working (or rather, school) days, which previous shutdown laws in China and South Korea did not attempt to do. This new regulatory position is undoubtedly particularly restrictive and pushing new boundaries.

The NPPA has officially provided certain additional background information as to why the regulations in the 2021 Notice were imposed. ${ }^{4}$ Two points are worth highlighting. Firstly, the NPPA stated that 'not a few' parents have reported that they thought that the requirements set out in the 2019 Notice were overly lenient and should be reduced (which is why the 2021 Notice was published). Secondly, the NPPA stated that the reason why any video gaming was permitted at all was because 'some' teachers and parents have reflected that moderate engagement with video gaming is understandable and acceptable. This suggests that the NPPA views permitting any video gaming by minors as a concession to the minority of teachers and parents holding a positive view of video gaming. Empirical study of what Chinese parents, children and teachers think about the regulations set out in the 2019 Notice and about the potential benefits and harms video gaming would be a worthwhile pursuit that remains to be conducted. Further, it remains unknown whether it would have been more beneficial to the minors had they been permitted to choose when to use their three weekly hours of video gaming (e.g., one single larger chunk of video gaming per week may fit better with their academic schedule and thus better promote their learning and their time-management skills), rather than be permitted only to play video games during three specific hours of the week.

\subsection{Diverging from the South Korean Regulatory Position}

This regulatory development in China comes at a particularly noteworthy time: South Korea, the only other country that has imposed a similar shutdown law prohibiting minors under the age of 16 from playing video games between midnight and 6:00 the next morning since 2011 (which was assessed to be ineffective as it failed to reduce internet usage and failed to increase sleeping hours ${ }^{5}$ ), will be

\footnotetext{
${ }^{4}$ 国家新闻出版署 [National Press and Publication Administration (PRC)], 国家新闻出版署有关负责人 就《关于进一步严格管理切实防止末成年人沉迷网络游戏的通知》答记者问 [Responses Provided by the Relevant Person in Charge at the National Press and Publication Administration to Questions Posed by Journalists in relation to the Notice on Further Strictly Regulating and Effectively Preventing Online Video Gaming Addiction in Minors] (2021), http: / / www.nppa.gov.cn/nppa/ contents / 719/98788.shtml (last visited Aug 30, 2021).

${ }^{5}$ See Jiyun Choi et al., Effect of the Online Game Shutdown Policy on Internet Use, Internet Addiction, and Sleeping Hours in Korean Adolescents, 62 Journal OF AdOLESCENT HeALTH 548-555 (2018).
} 
abolishing that law by the end of 2021, in favour of a voluntary self-exclusion system. ${ }^{6}$ The forthcoming abolition of the South Korean shutdown law was motivated by the South Korean Government's desire to better respect the minors' right to self-determination, right to pursue happiness, and right to 'be educated at home' (possibly implying the parents' right to educate their children at their discretion within reason). ${ }^{7}$ The benefits of video gaming for providing entertainment and helping children to socialise and communicate were explicitly recognised by the South Korean Minister of Culture, Sports and Tourism. ${ }^{8}$ The official announcement that South Korea will be abolishing its shutdown law came less than a week before the 2021 Notice was published in China. Countries in Far East Asia have often been perceived as taking similarly restrictive approaches to video games, especially in relation to minors (which has largely been true): however, it seems that various Far East Asian countries' regulatory policies are now diverging.

\subsection{Potential Loopholes Remain Open}

The 2021 Notice would continue to face practical enforcement issues that arose in relation to the 2019 Notice and remain unresolvable. One loophole is that parents (and other adults around the minor), if they so choose, can still give their adult identity-verified accounts to the minor for them to play the games without restrictions. Adults may also inadvertently give access to their accounts to minors: e.g., if they forgot to log-out at the end of their own play session. Another loophole is that minors can purchase adult identity-verified accounts online through popular ecommerce website and use those accounts to play unrestricted. Facial recognition (upon initial log-in of the account and at intervals during gameplay) has been adopted by some video game companies to 'catch' children using adults' accounts; ${ }^{9}$ however, the 2021 Notice has not explicitly required companies to implement such

\footnotetext{
${ }^{6}$ Im Eun-byel, Korea to ax games curfew, THE KOREA HeRALD (2021), http: / / www.koreaherald.com/ view.php?ud=20210825000854 (last visited Aug 30, 2021).

7 문화체육관광부 [Ministry of Culture, Sports and Tourism (South Korea)], 보도자료 - 게임 셧다운제 폐지, 자율적 선택으로 과몰입 방지 유도 | 문화체육관광부 [Abolishing the game shutdown system, encouraging and preventing over-immersion through voluntary choice] (2021), https://www.mcst.go.kr/kor/s_notice/press/pressView.jsp?pSeq=19030 (last visited Aug 30, 2021). ${ }^{8} I d$.

${ }^{9}$ Tiffany May \& Amy Chang Chien, Game Over: Chinese Company Deploys Facial Recognition to Limit Youths' Play, THE NEW YORK TIMES, July 8, 2021, https: / / www.nytimes.com/2021/07/08/business/video-game-facial-recognition-tencent.html (last visited Aug 30, 2021).
} 
safeguarding systems. Additionally, the playing of video games on non-Chinese servers, potentially (but not necessarily) with the assistance of virtual private networks (VPNs), remain unregulated. The percentage of underage players that actively circumvent video gaming regulations through these loopholes (or have attempted to do so) is not known. Finally, it should be noted that the playing of offline video games (e.g., many single-player console games) remains unregulated, possibly due to difficulties with enforcement.

\subsection{What Should Companies Do Now?}

The foremost, immediate concern is likely that the game servers may be unable to cope with the sheer number of users logging-on to play the games during the three specified hours: in the past, user activity would have been dispersed across various time slots, but now all underage users will be attempting to play the game during the three specified hours. Game companies should prepare for potentially unprecedented peaks in user activity.

In the longer-term, the 2021 Notice may well bring fundamental changes to how video games are designed and monetised. For example, it would now be impossible for minors to obtain daily log-in bonuses that reward the player for logging-into the game every day, which are implemented by companies to encourage frequent, daily engagement with the game and retain users. Similarly, the popular monetisation method of season passes, ${ }^{10}$ whereby the player is rewarded for sustained dedication to the game over an extended period of time, will no longer be appealing to underage players because they would never have enough time to complete the season passes. Video game companies would need to evaluate how their games can be redesigned to still be appealing and profitable in relation to minors, despite the gameplay time restrictions.

For some companies at least, the underage Chinese userbase likely should be entirely abandoned because of the associated compliance costs. Tencent, the largest video game company in China (and in the world), revealed in its latest interim financial results that: 'During the second quarter of 2021, players aged under 16 accounted for $2.6 \%$ of our China game grossing receipts. Among which, players

\footnotetext{
${ }^{10}$ Elena Petrovskaya \& David Zendle, The Battle Pass: a Mixed-Methods Investigation into a Growing Type of Video Game Monetisation (2020), https: / / osf.io/ vnmeq/ (last visited Aug 30, 2021).
} 
aged under 12 accounted for $0.3 \%$.' Unhelpfully, the amount of revenue that players between 16 and 18 generates was not revealed. Assuming that this is similarly insignificant (say less than 5\%), then the compliance costs associated with restricting underage players' access may overweigh the potential profits that can be generated from them.

\section{Conclusion}

This regulatory development in China should also serve as a warning to video game companies operating in other countries: lack of adequate industry self-regulation and transparency may lead to legal overregulation. Earlier in August 2021, Tencent had tried to impose industry self-regulations that were more restrictive than the 2019 Notice's requirements in China; ${ }^{11}$ however, it seems that Tencent's gesture came too late to prevent the even more stringent requirements of the 2021 Notice from being subsequently imposed. The loot box situation, i.e., whether randomised, gamblinglike monetisation methods in video games should be regulated by law, may well develop in a restrictive direction that is undesirable to the video game industry in many countries (including Western countries), if proactive consumer protection efforts are not forthcoming from the industry. ${ }^{12}$ More specifically, the Chinese Government's increasing efforts to regulate video games may also mean that loot box probability disclosure legal requirements would now be more strictly enforced. ${ }^{13}$

\section{Conflict of Interest}

LYX was employed by LiveMe, a subsidiary of Cheetah Mobile (NYSE:CMCM) as an in-house counsel intern from July to August 2019 in Beijing, People's Republic of China. LYX was not involved with the monetisation of video games by Cheetah Mobile or its subsidiaries.

\footnotetext{
11 王者运营团队 [Honour of Kings Operations Team], 王者荣耀健康系统升级公告 [Honour of Kings Health System Upgrade Notice] (2021), https: / / pvp.qq.com/web201706/ newsdetail.shtml?tid=527202 (last visited Aug 30, 2021); See also Josh Ye, Tencent narrows kids' playing time on flagship game Honour of Kings, SOUTH CHINA MORNING POST (2021), https: / / www.scmp.com/tech/bigtech/article/3143779/ tencent-cuts-kids-playing-time-flagship-game-honour-kings-appease (last visited Aug 30, 2021).

${ }^{12}$ Leon Y. Xiao, Regulating Loot Boxes as Gambling? Towards a Combined Legal and Self-Regulatory Consumer Protection Approach, 4 INTERACTIVE ENTERTAINMENT LAW REV. 27-47 (2021).

${ }^{13}$ See Leon Y. Xiao et al., Gaming the system: suboptimal compliance with loot box probability disclosure regulations in China, Advance Online Publication, BEHAVIOURAL PUBLIC POLICY 1-27 (2021).
} 